\title{
On a vibratory motion at the origin of a jet of vapour
}

\section{M.Th. Vautier}

To cite this article: M.Th. Vautier (1882) On a vibratory motion at the origin of a jet of vapour, Philosophical Magazine Series 5, 13:81, 306-306, DOI: 10.1080/14786448208627184

To link to this article: http://dx.doi.org/10.1080/14786448208627184

曲 Published online: 28 Apr 2009.

Submit your article to this journal $\pi$

Џll Article views: 2

Q View related articles $\square$ 


\section{ON A VIBRATORY MOTION AT THE ORIGIN OF A JET OF VAPOUR. BY M. TH. VAUTIER.}

In the course of some researches which I have commenced upon the flow of gases and vapours, I have observed a singular phenomenon, which was first signalized in 1826 , by an engineer of Fouchambault's iron-works:-When a jet of gas or vapour flows, under pressure, through an orifice, if a plate be placed normal to the axis of the jet, at a certain height, it is repelled; but when the plate is lowered parallel to itself, it is attractod, and spontaneously supports itself at about 0.2 millim. from the orifice, oscillating about a position of equilibrium and emitting a sound.

I have succeeded, by means of a very simple arrangement, on fixing some plates in that situation, in making them give forth sounds high, intense, as prolonged as I pleased, and directly register those vibrations. I have obtained in the tracings, undulations of remarkable regularity and amplitude.

I have directly registered the vibrations, thus kept up by a jet of vapour, of a plate giving a note close to the $l a{ }_{6}=7250$ single vibrations per second. An electrodiapason simultaneously registered its vibrations. Pressure in the boiler, $4.5 \mathrm{~atm}$. ; diameter of the orifice, $2 \cdot 7$ millim. Diameter of the plate, 6 millim. ; thickness, 1.5 ; distance from the orifice, 0.2 ; amplitude of the vibrations, $0 \cdot 7$. Thus, then, we have a chronograph directly registering $\frac{1}{72} \overline{5}$ of a second.

The sound which I get is intenser than that of the diapasons which give the same note, and of which it has not, up to the present, been possible to sustain the motion electrically in a practical manner, and, consequently, to register it continuously. The apparatus which I have prepared traces, as long as I please, in sharp outline, regular vibrations of sufficient amplitude to be subdivided in the usual manner. This subdivision is facilitated by the fineness of the tracing, which is obtained by means of very sharp styles, which, pressed lightly upon sheets of mica either smoked or not, leave a thin stroke engraved upon those surfaces.

Hitherto, at least to my knowledge, it has been found possible at most to register, directly and continuously, the thousandth part of a second, which is afterwards divided. The apparatus which $I$ use registers directly the seven-thousandth of a second; and the tracing, very thin, favours the usual divisions. The results obtained by me quite recently permit me to expect to register sounds of still higher pitch. I purpose to apply this chronograph to the measurement of some rapid phenomena. - Comptes Rendus de l'Académie des Sciences, March 6, 1882, t. xciv. p. 642.

ON THE COMPRESSIBILITY OF GASES. BY M. E. SARRAU.

1. In a memoir on the compressibility and expansion of carbonic acid, very important when regarded from the thermodynamic point of view, M. Clausius has proposed for this gas the following relation between the pressure $(p)$, the volume $(v)$, and the absolute temperature $(\mathrm{T}):-$

$$
p=\frac{\mathrm{RT}}{v-\alpha}-\frac{\mathrm{K}}{\mathrm{T}(v+\beta)} \cdot . . . . \cdot
$$

